\title{
Conversion of 1,3-Propylene Glycol on Rutile
}

\section{$\mathrm{TiO}_{2}(110)$}

\author{
Long Chen, Zhenjun Li, ${ }^{\dagger}$ R. Scott Smith, Bruce D. Kay, Zdenek Dohnálek*
}

Fundamental and Computational Sciences Directorate and Institute for Integrated Catalysis,

Pacific Northwest National Laboratory, P.O. Box 999, Mail Stop K8-88, Richland, Washington

99352, United States 


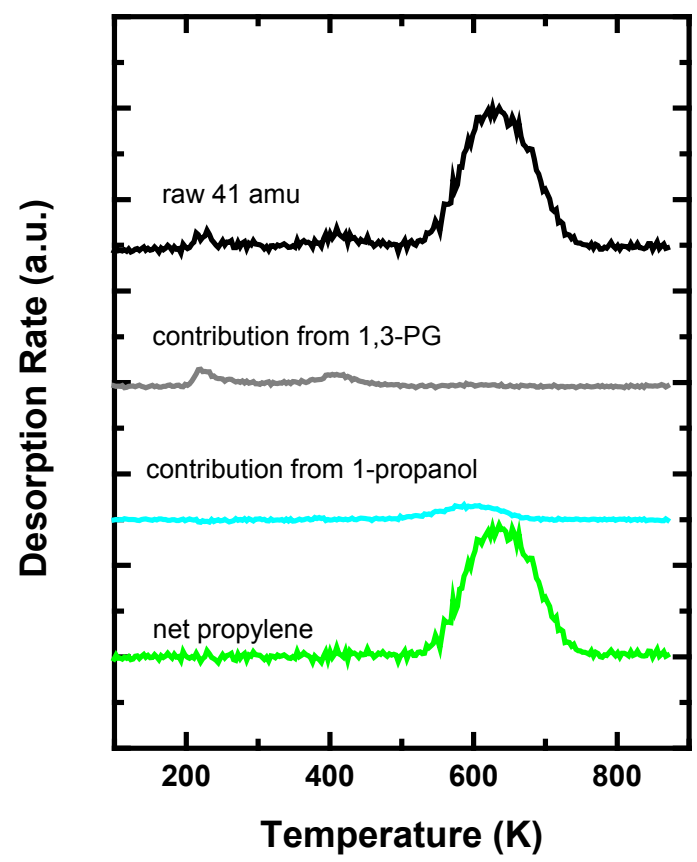

Figure S1. The reaction products arising from the interaction of 1,3-PG with $\mathrm{TiO}_{2}(110)$ are determined using mass spectrometry. Due to fragmentation that occurs during electron ionization, the mass used to determine the product yield is not the parent mass but instead it is typically a fragment mass that has the largest signal and the fewest contributions from other products. Because the assigned $\mathrm{m} / \mathrm{z}$ signals can have contributions from several sources, the raw signals must be corrected to determine the true product yields. Here we demonstrate the process for determining the product yield for propylene. A similar process was used for determining the yields of the other products.

The top trace is the uncorrected mass $41 \mathrm{TPD}$ signal from an experiment where $0.7 \mathrm{ML}$ of 1,3-PG is deposited on $\mathrm{TiO}_{2}(110)$ and heated at $1 \mathrm{~K} / \mathrm{s}$. Mass 41 was the primary fragment used to determine the product yield of propylene. In addition to fragments from propylene, the mass 41 signal has contributions from 1,3-PG and 1-propanol. To make the correction for the 1,3-PG, the ratio of mass 45 and mass 41 signals observed during the desorption of unreacted 1,3-PG was determined. This was done using multilayer coverages where it is clear there is no contact with the surface. Mass 45 has contributions only from 1,3-PG. The 1,3-PG contribution to the mass 41 signal is calculated by multiplying the mass 45 signal by the (mass $41 /$ mass 45 ) ratio from pure 1,3-PG. This trace is labeled as "contribution from 1,3-PG" in the plot. The analogous process is repeated for the 1-propanol contributions to mass 41 using mass 31 and that trace is also shown. These two traces are subtracted from the raw signal to give the bottom spectrum, which is the final corrected spectrum for propylene. 


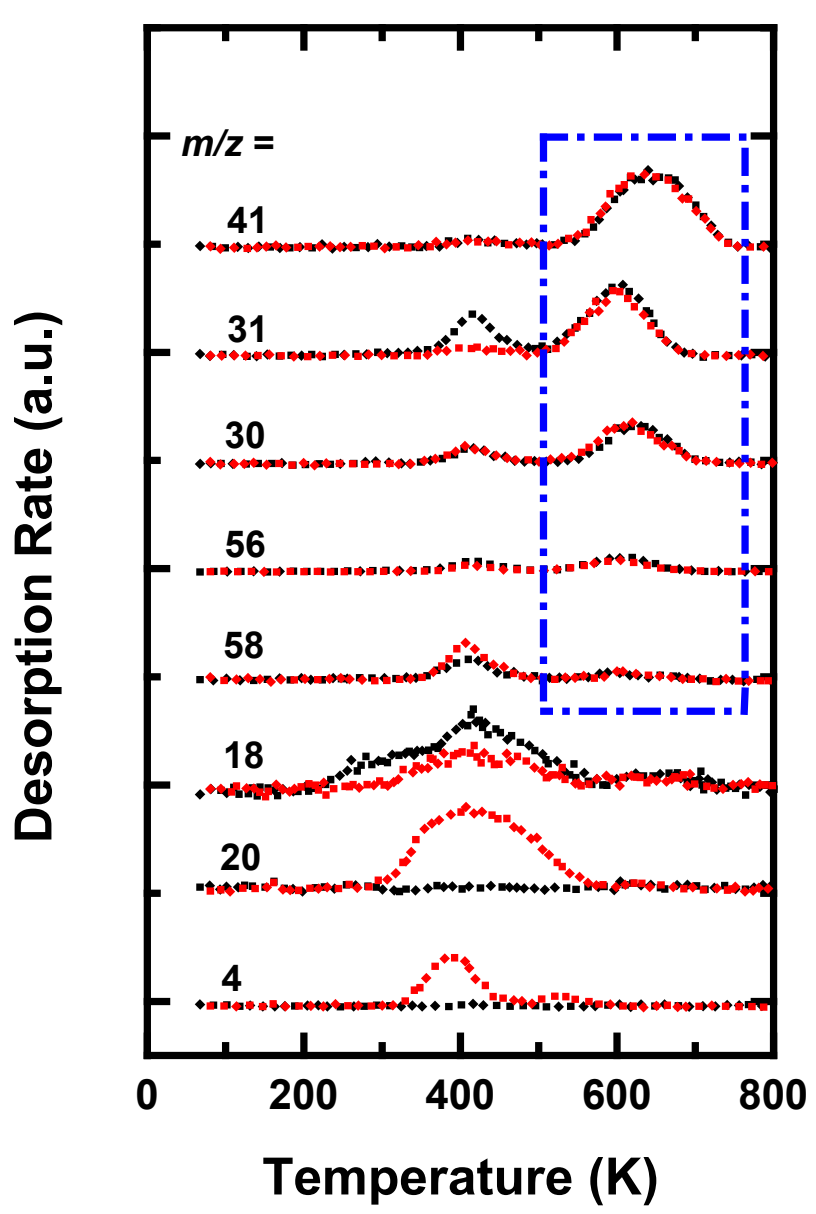

Figure S2. Major mass fragments observed during TPD from $0.5 \mathrm{ML}$ of (a) $\mathrm{HO}\left(\mathrm{CH}_{2}\right)_{3} \mathrm{OH}$ (black traces) and (b) $\mathrm{DO}\left(\mathrm{CH}_{2}\right)_{3} \mathrm{OD}$ (red traces) on $\mathrm{TiO}_{2}(110)$. The $\mathrm{DO}\left(\mathrm{CH}_{2}\right)_{3} \mathrm{OD}$ were prepared directly on $\mathrm{TiO}_{2}(110)$ using an $\mathrm{H} / \mathrm{D}$ exchange procedure which is described in detail in our recent publication. ${ }^{1}$ The desorption features highlighted by a rectangular box represent carboncontaining products formed during TPD. Note that essentially identical carbon-containing products are observed between $\mathrm{HO}\left(\mathrm{CH}_{2}\right)_{3} \mathrm{OH}$ and $\mathrm{DO}\left(\mathrm{CH}_{2}\right)_{3} \mathrm{OD}$, suggesting that hydroxyl hydrogens in 1,3-PG are not involved in these products, but released in the form of hydrogen and water.

\section{Reference}

1. Chen, L.; Li, Z.; Smith, R. S.; Kay, B. D.; Dohnalek, Z. Molecular Hydrogen Formation from Proximal Glycol Pairs on $\mathrm{TiO}_{2}(110)$. J. Am. Chem. Soc. 2014, 136, 5559-5562. 

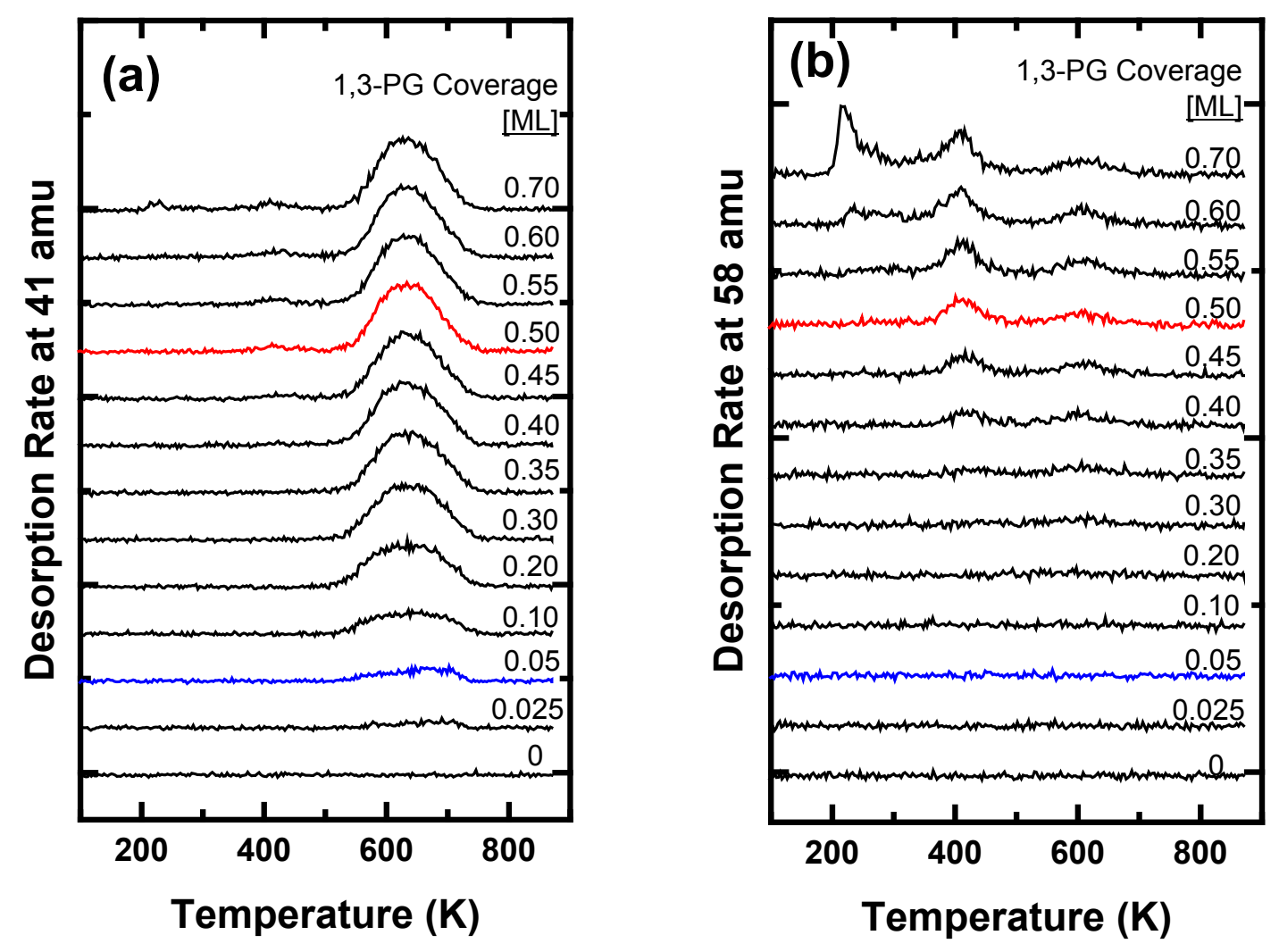

Figure S3. Coverage dependent TPD spectra obtained at (a) $m / z=41$ amu and (b) $m / z=58$ amu. TPD traces for the coverages that correspond to the $\mathrm{V}_{\mathrm{O}}$ concentration and saturation coverage on $\mathrm{Ti}_{5 \mathrm{c}}$ sites are highlighted with blue and red, respectively. 

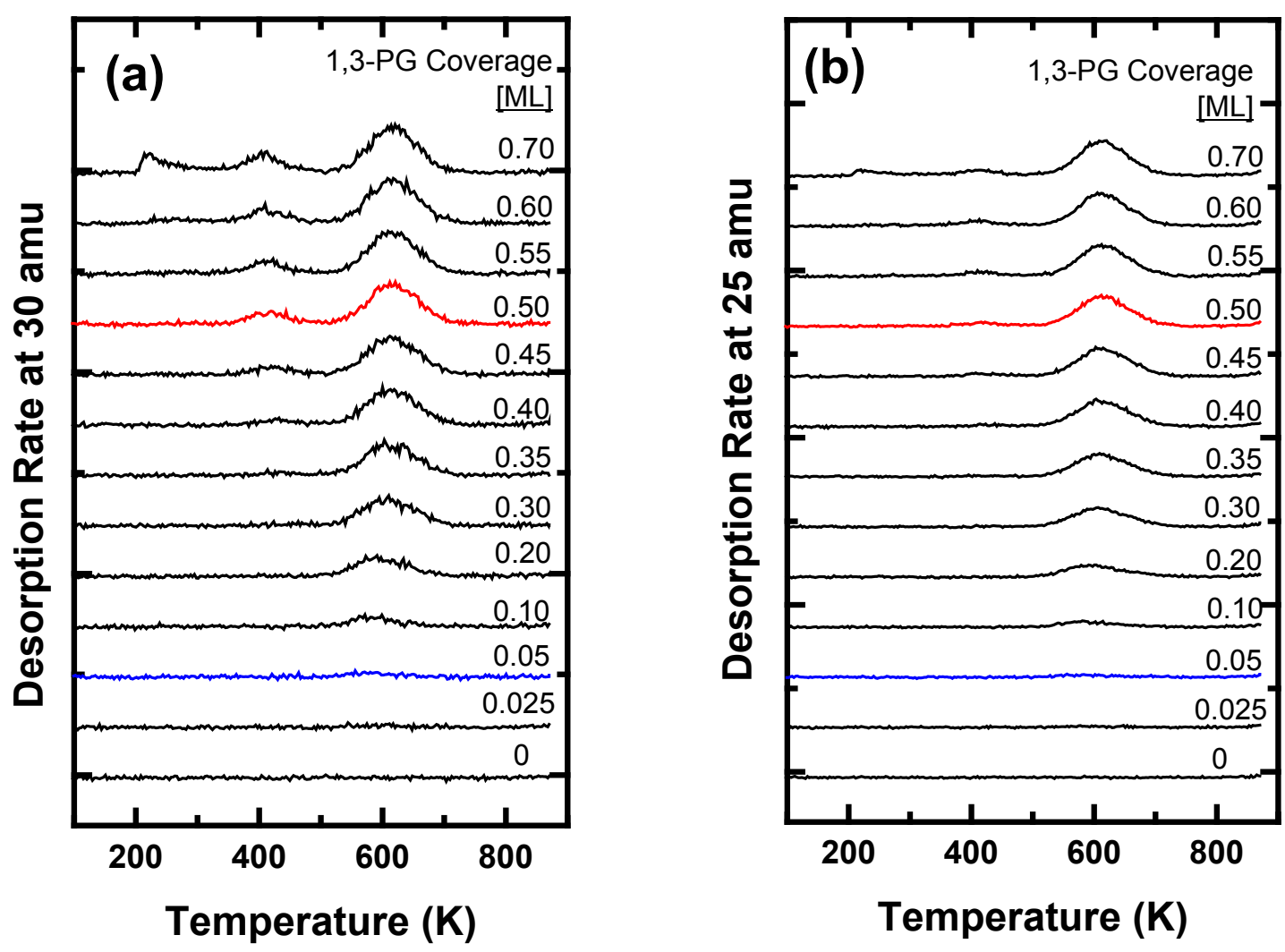

Figure S4. Coverage dependent TPD spectra obtained at (a) $\mathrm{m} / \mathrm{z}=30$ amu and (b) $\mathrm{m} / \mathrm{z}=25 \mathrm{amu}$. TPD traces for the coverages that correspond to the $\mathrm{V}_{\mathrm{O}}$ concentration and saturation coverage on $\mathrm{Ti}_{5 \mathrm{c}}$ sites are highlighted with blue and red, respectively. 

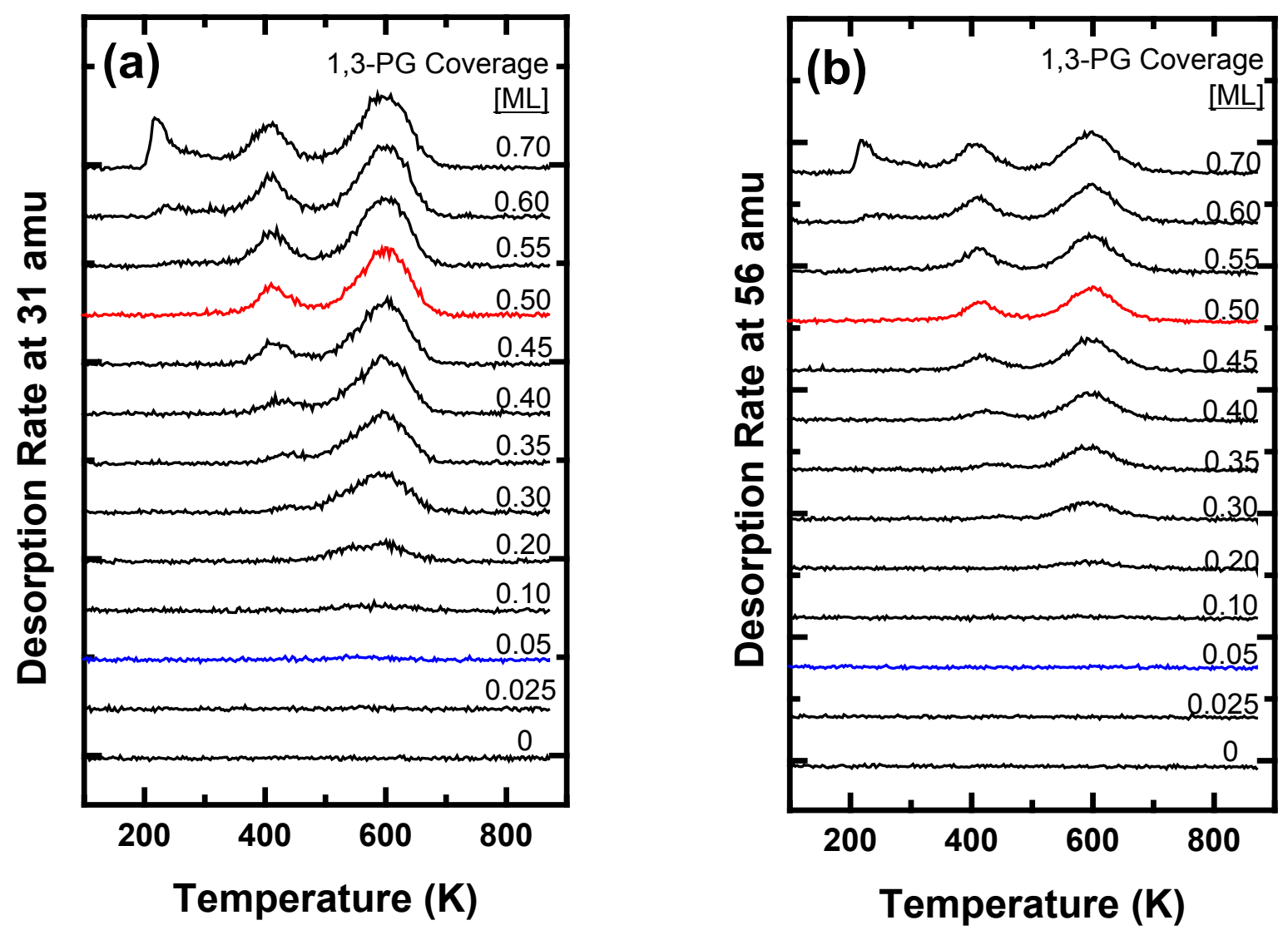

Figure S5. Coverage dependent TPD spectra obtained at (a) $\mathrm{m} / \mathrm{z}=31$ amu and (b) $\mathrm{m} / \mathrm{z}=56 \mathrm{amu}$. TPD traces for the coverages that correspond to the $\mathrm{V}_{\mathrm{O}}$ concentration and saturation coverage on $\mathrm{Ti}_{5 \mathrm{c}}$ sites are highlighted with blue and red, respectively. 


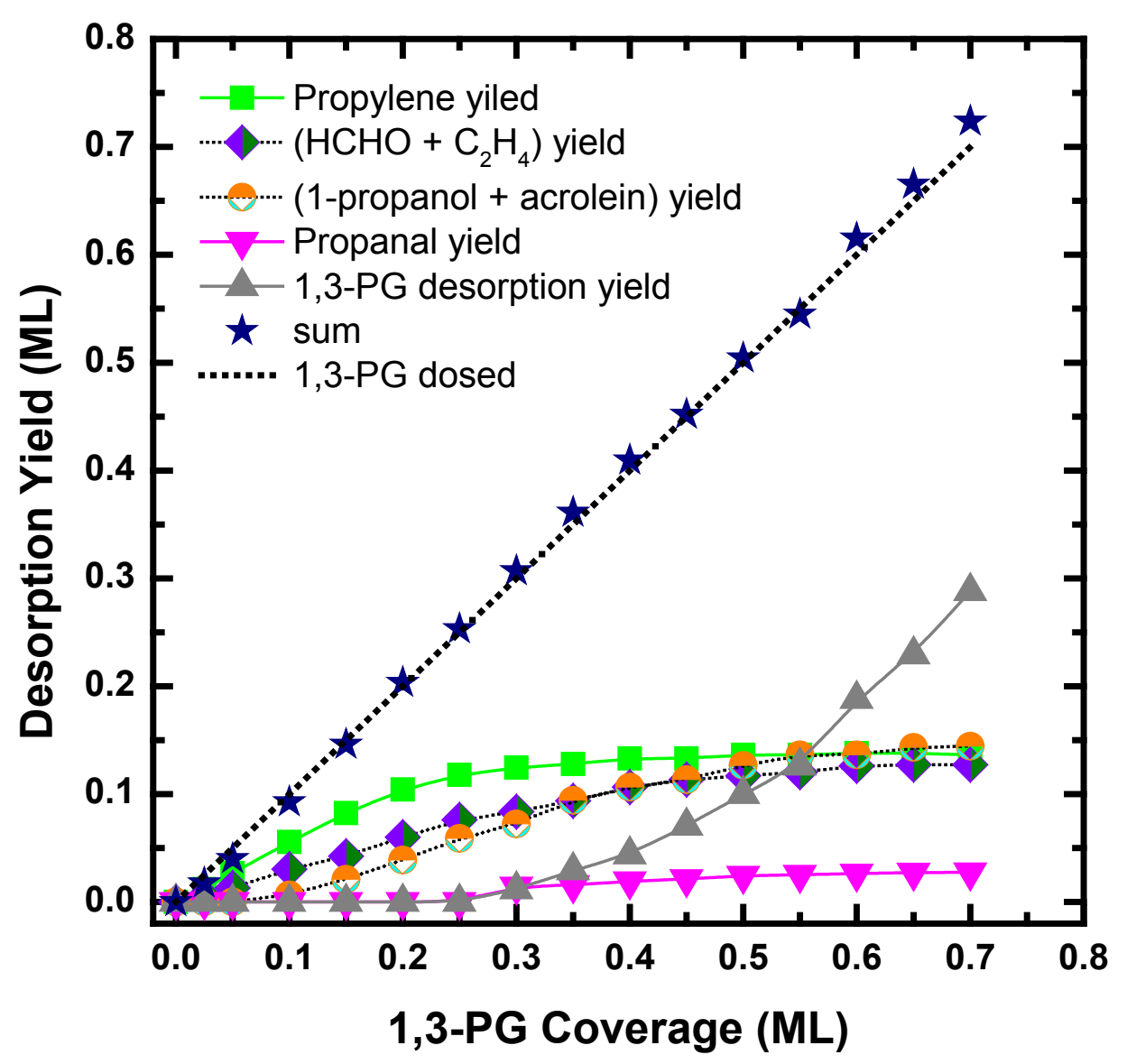

Figure S6. Integrated yields of desorbing propylene (squares), $\mathrm{HCHO}+\mathrm{C}_{2} \mathrm{H}_{4}$ (diamonds), 1propanol + acrolein (circles), propanal (down triangles), 1,3-PG (up triangles) and their sum (stars) from the TPD spectra shown in Figures 3, 4, 5, and 7 as a function of 1,2-PG coverage. Short dot line in the figure represents the total amount of carbon deposited on the surface as a result of the 1,3-PG dose. 